\title{
THREE DIFFERING CASES OF GLYCOGEN STORAGE DISEASE
}

\author{
BY \\ D. G. WALKER, ${ }^{*}$ M. ZIAI and J. E. BOWMAN \\ From the Department of Biochemistry, University of Shiraz and Departments of Paediatrics and Pathology, \\ Shiraz Medical Centre, Nemazee Hospital, Shiraz, Iran
}

(RECEIVED FOR PUBLICATION NOVEMBER 14, 1960)

More than 30 years have elapsed since von Gierke (1929) gave the first comprehensive account of clinical and pathological studies on cases in which large deposits of glycogen could be found in the liver and kidneys. Many cases have been reported since then and differing types of glycogen storage disease have been recognized so that a group of diseases each having their characteristic abnormalities is now known (Mason and Andersen, 1941; Cori, 1954). Recent advances in our knowledge of certain aspects of carbohydrate metabolism, in particular the enzymic synthesis and degradation of glycogen, has led to the belief that the group of diseases is caused by differing defects or deficiencies of certain enzymes, these abnormalities being controlled by genes of a mendelian recessive type.

The purpose of this report is to describe three cases of glycogen storage disease each of which has been the result of a consanguinous marriage. The three cases differ. Whilst it has not proved possible to perform all the desirable biochemical studies, observations on certain aspects of carbohydrate metabolism as revealed by intravenous galactose tolerance tests on the three cases are reported.

\section{Case Reports}

Case 1. H.M., an Iranian male, was first admitted to the Nemazee Hospital as an infant of 9 months in October 1958. The chief complaint was abdominal distension and diarrhoea. The mother's pregnancy and delivery of the baby had been normal. The infant developed jaundice at 3 days of age which seems to have been physiological, and an exanthem at 3 months of age was diagnosed as measles. About the same time the child had an episode of generalized convulsions lasting about 15 minutes, but the details are not clear. The mother noticed progressive abdominal distension and nocturnal low grade fever. Ten days before admission another episode of convulsions occurred

\footnotetext{
* Now at the Department of Biochemistry, University of Birming ham, Edgbaston, Birmingham 15.
}

during the night. It is stated that the child had had mild diarrhoea and occasional vomiting since birth which at one time necessitated a period of 25 days in hospital. The father is 32 years and the mother 20 years old. The parents are first cousins. The patient has a 4-year-old healthy sister and the only other sibling was a girl who died at 4 months of 'pneumonia'.

On admission the temperature was $36.5^{\circ} \mathrm{C}$. and the respiratory rate was 33 per minute. The patient weighed $6.98 \mathrm{~kg}$., his height was $65 \mathrm{~cm}$. and the head circumference was $43 \mathrm{~cm}$. He appeared small and undernourished but in no distress. The liver was palpable $7 \mathrm{~cm}$. below the right costal margin and had a firm smooth consistency. There were no other positive physical findings.

Chest radiograph and barium swallow for oesophageal varices showed no abnormalities. An intravenous pyelogram showed moderate hydronephrosis of the right kidney. The liver appeared to be enlarged on the radiographs, but no splenomegaly was noted. The tuberculin test was negative. Urinalysis showed a moderate amount of acetone and a trace of albumin. The fasting blood sugar level ranged between 7 and $95 \mathrm{mg}$. per $100 \mathrm{ml}$., the total cholesterol ranged between 260 and $300 \mathrm{mg}$. per $100 \mathrm{ml}$. and $\mathrm{CO}_{2}$ determinations gave values between 6 and $21 \mathrm{mEq}$ per litre. Serum albumin was $5 \mathrm{~g}$. per $100 \mathrm{ml}$. and serum globulin was $3 \mathrm{~g}$. per $100 \mathrm{ml}$. Electrophoresis of the serum proteins was normal. Total bilirubin was $1.4 \mathrm{mg}$. per $100 \mathrm{ml}$. with a direct value of $0.25 \mathrm{mg}$. per $100 \mathrm{ml}$. The thymol turbidity was high, 23 units, but the cephalin-cholesterol flocculation test was negative. Haemoglobin was $12 \cdot 1 \mathrm{~g}$. per $100 \mathrm{ml}$. and the W.B.C. count was 13,200 per c.mm. with $15 \%$ segmented neutrophils, $76 \%$ lymphocytes and $9 \%$ monocytes. The prothrombin time was normal.

During the period in hospital the patient had repeated bouts of respiratory and urinary tract infections which were proven by cultures and treated by antibiotics. $\mathrm{He}$ had several episodes of hypoglycaemia and severe acidosis which could be relieved by frequent feedings with a high protein diet and by sodium bicarbonate. The biochemical studies were made when the patient was in a good condition and had been free of the above problems for several days.

An exploratory laparotomy was performed under general anaesthesia on December 2, 1958. There was 
massive enlargement of both lobes of the liver, which was soft in consistency and a pale pinkish yellow in colour. There was no peritoneal fluid. The spleen could not be palpated through the right upper quadrant incision and the gall bladder was normal. A biopsy specimen of liver tissue was obtained and the patient tolerated the whole procedure quite well. Histological examination of the liver tissue showed parenchymal cells that contained much fat (stained with Oil red $\mathrm{O}$ ). The fat cells ranged from small to medium to large; fat cysts were present in some regions. Many parenchymal cells had a clear cytoplasm. These cells contained a PAS positive substance which did not react with PAS after incubation of the tissue preparations with diastase. There was moderate fibrosis but no evidence of cirrhosis.

After discharge from hospital, frequent out-patient examinations showed continued poor development and susceptibility to infections, acidosis and hypoglycaemia.

On September 21, 1959, the patient was readmitted to the hospital for the last time with severe pneumonia and in a comatose state. He did not respond to various kinds of supportive therapy, including antibiotics, intravenous glucose and alkali, and oxygen. He died on September 26, 1959. An autopsy could not be performed.

Case 2. A.D., an Iranian male, was brought to the Nemazee Hospital in January 1958, when 2 years old. He was the product of a normal pregnancy and delivery except for a few days spotting during the second month. The parents noted some protuberance of the abdomen mainly in the right upper quadrant at 2 months of age and this had been progressive particularly during the six months before admission. The child's appetite, feeding and development were described as normal. Four or five attacks of mild diarrhoea occurred during the first year of life. He had a bout of otitis media when 18 months old which had been treated successfully.

The parents were first cousins. The mother had had a total of seven pregnancies, four children still being alive. These included the patient, one healthy boy and two healthy girls. Of the three children who had died, one is said to have had the same kind of abdominal distension and died of an unknown cause when 2 years old. There is no history of abortions. The family lived in a village, drank well water and were poor economically.

On admission the temperature was $37 \cdot 2^{\circ} \mathrm{C}$. (rectally), the pulse rate 120 per minute, respirations 22 per minute, weight $7.05 \mathrm{~kg}$., and head circumference $44 \mathrm{~cm}$. The child appeared underdeveloped, undernourished and chronically ill, but in no acute distress. The teeth were carious. The protuberant abdomen on palpation revealed a large firm non-tender mass filling the right abdomen down to the iliac crest and extending obliquely to a point about three finger breadths below the right costal margin. Rectal examination was non-contributory.

X-ray studies including chest examination, barium enema, upper gastrointestinal series and intravenous pyelogram were all negative. The haemoglobin was
10.6 g. per $100 \mathrm{ml}$. and the W.B.C. count was 11,750 per c.mm. The urine was yellow and cloudy, had an acid $p \mathrm{H}$ and always contained acetone. A trace of albumin and a trace of sugar was detected on one occasion. The fasting blood sugar level ranged between 50 and $85 \mathrm{mg}$. per $100 \mathrm{ml}$. and the blood cholesterol was $420 \mathrm{mg}$. per $100 \mathrm{ml}$. The thymol turbidity was again high, 27 units, but the cephalin-cholesterol flocculation test was negative. The tuberculin test was negative. Further biochemical studies will be described later.

An exploratory laparotomy was performed and revealed a huge liver extending into the right lower quadrant. All the lobes were enlarged and the liver surface was smooth and pale. A biopsy sample was taken. The abdomen contained a minimal amount of fluid, a culture of which was negative. There appeared to be some ascaris in the small bowel. During surgery the patient developed marked slowing of the heart, but soon recovered and the condition became satisfactory. The post-operative course was uneventful.

Histological examination of the liver specimen showed parenchymal cells that were quite large, but variable in size and shape with a clear cytoplasm. Tissue sections were stained with Oil red $O$ and PAS before and after incubation with diastase. The sections stained for fat showed minimal droplets scattered throughout the parenchymal cells; the droplets were not large. The sections stained with PAS were positive before but negative after incubation with diastase. There were occasional fine strands of fibrous connective tissue extending from the portal regions into scattered lobules, but there was no cirrhosis.

The patient left the hospital in March 1958, in good condition having gained $3 \mathrm{lb}$. whilst in hospital, but contact with this patient has since been lost.

Case 3. Z.E., an Iranian girl, was brought to the Nemazee Hospital in October 1957, when $4 \frac{1}{2}$ years old because of enlargement of her abdomen. Pregnancy and delivery had been normal. The child had been breast fed for only three months and had then been placed on whole cow's milk. Development had been slow. She sat up at 1 year, began to talk at 2 years and to walk at 3 years of age. She was well during the first six months of life, but then enlargement of the abdomen was first noticed. About the same time a skin infection had developed on her back which improved after six months of therapy. She had an attack of otitis at $3 \frac{1}{2}$ years of age and had had a few minor respiratory infections. The enlargement of the liver was described as having been progressive until the time of admission to hospital. The one remarkable fact about the family history was that the parents were second cousins.

On admission physical examination showed a temperature of $36 \cdot 4^{\circ} \mathrm{C}$. (axilla), pulse rate 120 per minute, respirations 34 per minute, weight $10 \mathrm{~kg}$. and height $76 \mathrm{~cm}$. The child appeared to be underdeveloped, but otherwise well nourished, was a little obese but did not look ill. The only positive physical findings were the markedly protuberant abdomen and a firm non-tender liver extending $6 \mathrm{~cm}$. below the right costal margin. 
The liver had a smooth surface and a firm consistency. Rectal and neurological examinations were within normal limits. Various radiological studies including chest films, intravenous pyelogram, barium enema and bone survey were negative except for the enlarged liver.

The haemoglobin was $11.5 \mathrm{~g}$.per $100 \mathrm{ml}$. and the W.B.C. count was 18,100 per c.mm., with $36 \%$ polymorphs, $63 \%$ lymphocytes and $1 \%$ monocytes. The prothrombin time was normal. The tuberculin test was negative. Urinalysis revealed a straw-coloured urine of acid $p \mathrm{H}$, specific gravity 1,015 containing neither albumin nor sugar, but significant amounts of acetone were always present. The fasting blood sugar ranged between 60 and $120 \mathrm{mg}$. per $100 \mathrm{ml}$., the blood cholesterol was 190 mg. per $100 \mathrm{ml}$. and $\mathrm{CO}_{2}$ was $16.2 \mathrm{mEq}$ per litre. Serum albumin was $4.0 \mathrm{~g}$. per $100 \mathrm{ml}$. and serum globulin $2.0 \mathrm{~g}$. per $100 \mathrm{ml}$. Thymol turbidity was 3.5 units and the cephalin-cholesterol flocculation was $1+$ after 48 hours. The total serum bilirubin was $0.2 \mathrm{mg}$. per $100 \mathrm{ml}$. The various tests on carbohydrate metabolism will be presented in a separate section.

An exploratory laparotomy was performed on November 16, 1957, which revealed a large liver with normal surface, colour and shape. There was about $10 \mathrm{ml}$. of clear fluid in the abdomen which gave a negative result on culture. The spleen was not enlarged and the rest of the abdominal organs appeared normal. The surgical procedure was tolerated well and the post-operative period was uneventful. A liver biopsy was obtained and histological examination showed changes essentially the same as in Case 2.

A muscle biopsy was obtained from the right gastrocnemius on December 4, 1957, under general anaesthesia. The muscle looked normal grossly and microscopic examination of the histological preparations revealed normal muscle tissue with no significant changes.

On March 11, 1958, a second laparotomy was performed and a liver biopsy specimen was taken for the estimation of glucose-6-phosphatase activity. Unfortunately, insufficient liver tissue was obtained to permit an estimation of the liver glycogen content. At this time the surgeon noted that the liver was appreciably larger than at the first laparotomy. Again there was some sterile serous fluid in the peritoneal cavity. Histological examination of the second biopsy specimen showed changes similar to those in the original material.

The child is being seen regularly in our clinic and is doing well except for a severe bout of pneumonia in May 1959, from which she recovered uneventfully. At this time she weighed $13.6 \mathrm{~kg}$. and the liver was noted to be about $8 \mathrm{~cm}$. below the right costal margin. On her last visit to hospital in May 1960, for a mild otitis media, she was in excellent general health and weighed $16 \cdot 1 \mathrm{~kg}$.

\section{Studies on Carbohydrate Metabolism}

Materials and Methods. The samples of liver tissue which were taken during laparotomy or at autopsy were frozen solid using dry ice and stored at $-20^{\circ} \mathrm{C}$. for not more than $\mathbf{2 4}$ hours until the assays of glucose-6phosphatase activity were performed essentially by the
TABLE 1

ASSAYS OF GLUCOSE-6-PHOSPHATASE ACTIVITY IN LIVER BIOPSY SPECIMENS OF THE THREE CASES AND TWO NORMAL LIVER CONTROLS

\begin{tabular}{c|c|c|c|c|c}
\hline $\begin{array}{c}\text { Liver Tissue in } \\
\text { Incubation Mixture } \\
\text { (mg./ml.) }\end{array}$ & \multicolumn{3}{|c|}{$\begin{array}{c}\text { Inorganic Phosphatase Liberated } \\
\text { ( } \mu \mathrm{g} . \text { P/100 mg. tissue) }\end{array}$} \\
\cline { 2 - 6 } & Case 1 & Case 2 & Case 3 & $\begin{array}{c}\text { Normal } \\
\text { A }\end{array}$ & $\begin{array}{c}\text { Normal } \\
\text { B }\end{array}$ \\
\hline 40 & 11 & 145 & 199 & 268 & 276 \\
20 & 18 & 166 & 264 & 449 & 410 \\
8 & 33 & 212 & 323 & 664 & 556 \\
\hline
\end{tabular}

method of Cori and Cori (1952) except that sodium citrate was used instead of potassium citrate and inorganic phosphate was determined by the method of Fiske and Subbarow (1925).

In the various tolerance tests to be described, blood was taken by heel puncture and withdrawn into a heparinized pipette. Glucose or total reducing sugar was determined by the Sunderman-Fuller macrotechnique described by Sunderman, Copeland, Macfate, Martens, Naumann and Stevenson (1956) after removal of the proteins with sulphuric acid and sodium tungstate. Galactose was determined after the removal of glucose by fermentation with yeast according to the method described by King and Wootton (1956). In the galactose tolerance tests, glucose was determined as the difference between the total reducing sugar and the equivalent reductng power of the galactose. Lactic acid was determined by the method of Barker and Summerson (1941) on the sulphuric acid sodium tungstate filtrates.

Glucose-6-phosphatase Assays. The results are shown in Table 1, which includes assays under identical conditions on liver samples from two control subjects who were undergoing laparotomy for other reasons. As noted by Cori and Cori (1952), less liver homogenate showed rather more than proportional effect. The results indicated marked differences between the three cases.

Glucose and Adrenaline Tolerance Tests. The amount of glucose administered intravenously was $1 \mathrm{~g}$. per $\mathrm{kg}$. body weight and adrenaline was given intramuscularly. The results of the tests are shown in Tables 2 and 3

TABLE 2

GLUCOSE TOLERANCE TESTS ON CASES 1, 2 AND 3: ALL FIGURES ARE mg. GLUCOSE per $100 \mathrm{ml}$. WHOLE BLOOD

\begin{tabular}{c|c|c|c}
\hline $\begin{array}{c}\text { Time } \\
\text { (min.) }\end{array}$ & Case 1 & Case 2 & Case 3 \\
\hline 0 & 10 & 50 & 60 \\
2 & 116 & 150 & $\frac{7}{120}$ \\
15 & 88 & 100 & 120 \\
40 & 60 & 50 & $\frac{76}{75}$ \\
60 & 46 & $=$ & $\frac{76}{76}$ \\
90 & 36 & $=$ & 74 \\
180 & $=$ & - & 64 \\
240 & & & \\
\hline
\end{tabular}


TABLE 3

ADRENALINE (EPINEPHRINE) TOLERANCE TESTS ON CASES 1, 2 AND 3: ALL FIGURES ARE mg. GLUCOSE per $100 \mathrm{ml}$. WHOLE BLOOD

\begin{tabular}{c|c|c|c|c}
\hline \multirow{2}{*}{$\begin{array}{c}\text { Time } \\
\text { (min.) }\end{array}$} & \multicolumn{2}{|c|}{ Case 1 } & Case 2 & Case 3 \\
\cline { 2 - 3 } & $\begin{array}{c}\text { Test } \\
\text { a }\end{array}$ & $\begin{array}{c}\text { Test } \\
\mathrm{b}\end{array}$ & & \\
\hline 0 & 3 & 32 & 50 & 76 \\
15 & 2 & 24 & 65 & 86 \\
30 & 8 & 22 & 60 & 100 \\
60 & 4 & 12 & 80 & 100 \\
120 & & & 60 & 70 \\
\hline
\end{tabular}

respectively. The glucose tolerance tests showed typical behaviour. In Case 1 there was no response to adrenaline, but Cases 2 and 3 showed small but significant increases in blood glucose following adrenaline administration.

Intravenous Galactose Tolerance Tests. In each test $1 \mathrm{~g}$. of galactose per $\mathrm{kg}$. body weight was administered intravenously during the course of two to three minutes in the form of a $20 \%$ aqueous sterile solution. The results for the three cases are shown in Figs. 1, 2 and 3 respectively. During the course of the tests, serious signs of acidosis were noted only in Case 1 where the lactic acid level was greatly elevated. The acidosis was controlled with sodium bicarbonate.

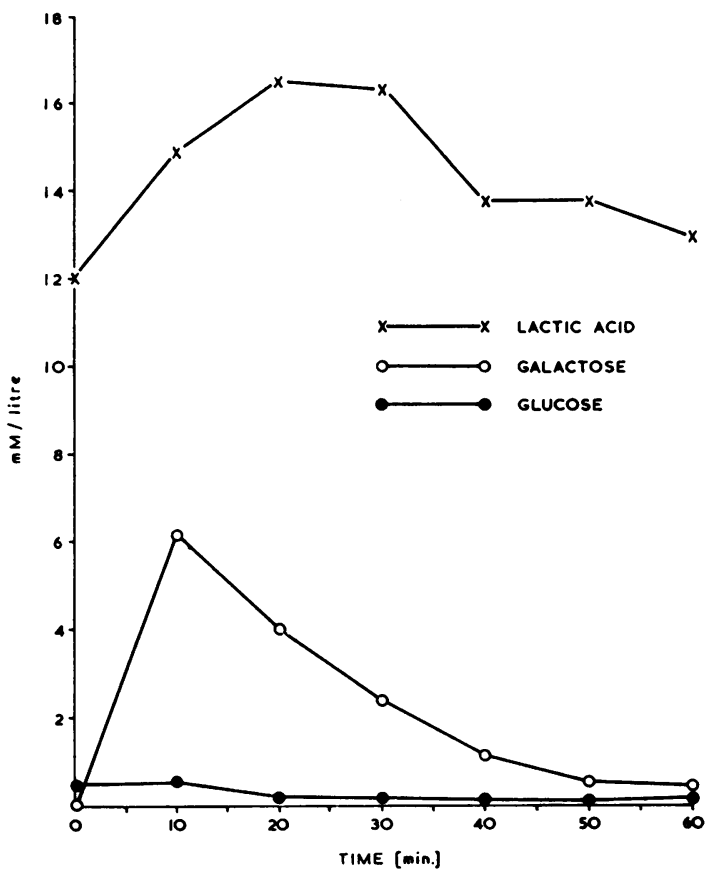

Fig. 1.-Galactose tolerance test on Case 1. Galactose $(1 \mathrm{~g}$. per $\mathrm{kg}$. $)$ was administered intravenously immediately after taking the zero time blood sample and over the course of the first three minutes. Further blood samples were taken at the times shown and assayed (see text).

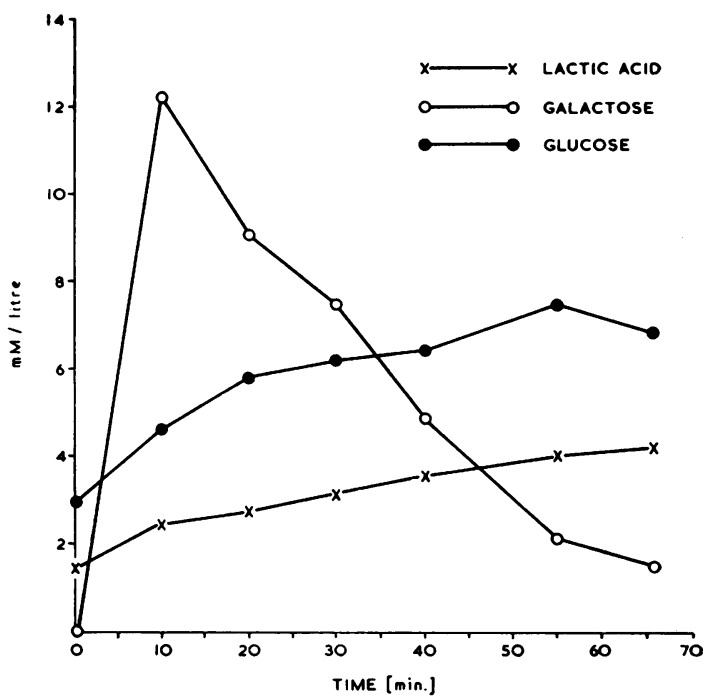

Fig. 2.-Galactose tolerance test on Case 2. Details as in Fig. 1.

\section{Discussion}

The family histories in all these cases are striking in that there is a history of consanguinity and also because of the possible occurrence of the disease in a sibling of Case 1 (H.M.) who had died at

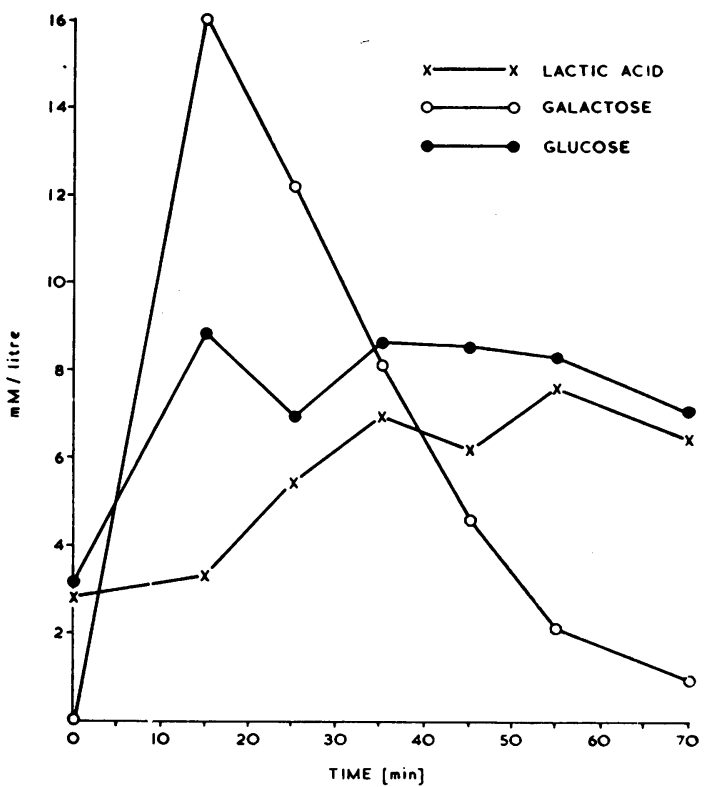

Fig. 3.-Galactose tolerance test on Case 3. Details as in Fig 1 
4 months of age of 'pneumonia', and in a sibling of Case 2 (A.D.) who had died with hepatomegaly. Unfortunately it has not proved possible to obtain very accurate information from the parents. These cases give strong support to the concept (van Creveld, 1939) that glycogen storage disease is transmitted by a recessive gene.

The diagnosis in all the cases of glycogen storage disease was based upon the clinical finding of poor development and hepatomegaly and the attacks of convulsions in Case 1 which were probably due to hypoglycaemic episodes. The laboratory findings of acetonuria and varying degrees of hypoglycaemia in all three cases as well as the microscopic examination of the liver biopsy specimens and the more extensive biochemical studies seem to establish the diagnosis on firm grounds.

The three cases were different. Our first case represented the severe and classical form of von Gierke's disease both from the points of view of clinical history and laboratory findings. Cases 2 and 3 were less severe cases from the clinical point of view and are alive and comparatively well. Andersen (1957) remarked that the variations in the degree of severity of the disease could be attributed mainly to variations in the glucose-6-phosphatase activity of the liver. This enzymic activity in our cases is discussed further below, but the almost normal level of glucose-6-phosphatase activity in Case 3 is one of several similarities to an atypical case described by Zetterström and Sörbo (1956) except that fat was not a prominent feature in our case. In fact, Cases 2 and 3 were indistinguishable histologically as against Case 1 which had the added feature of abundant fat in the liver including fat cysts. The absence of any cirrhosis in Case 3 excludes the possibility of it being a case with a glycogen of abnormal structure due to a deficiency of the 'branching' enzyme (amylo-1:4 $\longrightarrow 1: 6$ trans-glucosidase).

The results of the glucose-6-phosphatase assays revealed distinct differences between the three cases and confirmed the very severe condition of Case 1 . In Case 2, the enzymic activity was certainly not so low as in Case 1, but the values were below those of the normal controls and within the range of abnormal values quoted by Cori (1954). The glucose-6-phosphatase activity in Case 3 was higher than for the other two cases and clearly indicated that, while the activity was not quite so high as in the two normal controls, there was sufficient enzyme present to catalyse a significant production of glucose from glucose-6-phosphate. Cori (1954) also mentioned two cases of glycogen storage disease in which the glucose-6-phosphatase activity was almost normal. Storage of glycogen in increased 1 . quantities in the liver is therefore possible even in the presence of considerable amounts of the enzyme.

The intravenous glucose tolerance tests and the adrenaline tolerance tests agreed with the other findings. The use of galactose to examine the carbohydrate metabolism of these cases was employed by Mason and Andersen (1955) who fed galactose orally to a patient with von Gierke's disease and observed only a very small increase in the blood sugar level. Schwartz, Ashmore and Renold (1957) performed both oral and intravenous galactose tolerance tests on a patient in whom no production of inorganic phosphate could be demonstrated when a liver homogenate was incubated with glucose-6-phosphate. Using the oral test, these authors confirmed the findings of Mason and Andersen (1955) of very little increase in blood sugar level and marked lactic acidosis. Using the intravenous galactose tolerance the lactic acidosis was again seen and there was no formation of glucose from galactose. This latter result agreed with the finding of no glucose-6-phosphatase activity. In Case 1 of the present study in which glucose-6phosphatase activity was again very low, the results of the galactose tolerance test (Fig. 1) were very similar to those described by Schwartz et al. (1957), thus providing confirmatory evidence that this functional test might be used as a helpful diagnostic test for severe hepatorenal glycogen storage disease. However, in Case 2, diagnosed clinically as a less severe form of the same disease, the intravenous galactose tolerance test was different. There was slow steady production of glucose from galactose as might be expected from the demonstrated presence of some glucose-6-phosphatase activity. In Case 2 the initial lactic acid level was much lower than in Case 1 and the rate of lactic acid production was much less (Fig. 2). Thus the use of the intravenous galactose tolerance test as a diagnostic procedure for von Gierke's disease appears to be confined to cases where the glucose-6-phosphatase activity is very low or absent. It is also clear that those cases with a certain amount of glucose-6-phosphatase activity can form glucose even if in decreased quantities.

It is difficult, therefore, to see why there should be such excessive storage of glycogen in those cases with only some decrease in glucose-6-phosphatase activity. Formation of glucose from other sources such as amino acids has been described in cases of this type before. Lowrey and Wilson (1949) were able to raise the blood sugar level in a severe case by feeding gelatin. In Case 2, glucogenesis from galactose definitely occurred even though in reduced 
amounts compared to a normal individual. This implies that the problem of the source of the blood glucose in cases of von Gierke's disease may be confined largely to those cases where the glucose-6phosphatase activity is very low or absent.

The intravenous galactose tolerance test on Case 3 (Fig. 3) showed an immediate sharp rise in the blood glucose level resembling that demonstrated by Schwartz et al. (1957) on a normal child. A small increase in lactic acid was noted which differed from the normal case quoted, thus showing that the carbohydrate metabolism was not entirely normal in our atypical case. The lactic acid production is probably due to the high liver glycogen content preventing the normal conversion of galactose to glycogen. Case 3 is therefore of a type in which glycogen storage disease can arise and yet there be almost normal glucose-6-phosphatase activity and production of glucose from galactose. This seems to us to indicate that the glucose-6-phosphatase theory for von Gierke's disease does not apply in certain atypical cases. It would be interesting to know the results of the intravenous galactose tolerance test on the cases quoted by Cori (1954) and Zetterström and Sörbo (1956). It could be that the genetic defect is still concerned with glucose6-phosphatase but that, in certain atypical cases, alternative pathways of metabolism are developed to an increased extent.

This discussion so far has assumed that the milder forms of glycogen storage disease as seen in Cases 2 and 3 are due to the same genetic defect as the classical form of von Gierke's disease. These atypical cases may, however, be due to a deficiency of some other enzyme. Calderbank, Kent, Lorber, Manners and Wright (1960) have shown that in von Gierke's disease the liver contains high concentrations of the associated enzymes that act upon glucose-6-phosphate, namely phosphoglucomutase, glucose-6-phosphate dehydrogenase and phosphoglucose-isomerase. Synthesis of glycogen by a uridine diphosphate transferase system has been described by Leloir and Cardini (1957) in rat liver and by Hauk and Brown (1959) in rabbit muscle tissue. Hauk, Illingworth, Brown and Cori (1959) have shown that a deficiency of this enzyme cannot account for the generalized type of glycogen storage disease which also involves muscle tissue.

Hers $(1959 ; 1960)$ has offered evidence which suggests that a deficiency of the 'debranching' enzyme (amylo-1:6-glucosidase) may be the defect in these apparently mild cases of glycogen storage disease. He has shown, using a radio-isotope technique unlikely to be available to many clinical laboratories, that liver tissue from several cases with only a slightly lower than normal assay for glucose6-phosphatase has a virtually complete absence of amylo-1:6-glucosidase activity. A few other cases showed a deficiency in phosphorylase activity. This does suggest that such milder cases are due to a different defect from that in the classical form of von Gierke's disease. The defect is presumably due to a different gene which is probably also of the recessive type.

The results described also tend to confirm that the liver is the source of the lactic acid formed. Galactose is taken up rapidly from the systemic blood presumably by a galactokinase system in the liver. The galactose-1-phosphate thus formed will be converted via glucose-1-phosphate to glucose-6phosphate. Because the glucose-6-phosphate cannot be directly hydrolysed at the normal rate, increased glycolysis might be expected to occur which results in lactic acid production. This appears to be the only explanation of the increases in lactic acid levels after galactose administration. The lactic acid curve in Case 1 shows that lactic acid was being utilized towards the end of the experiment presumably by muscle and other peripheral tissues (Andersen, 1957). This can serve as an alternative and additional source of energy for these tissues. The demonstration of lactic acid utilization also shows how sodium lactate could still be used to treat acidosis in spite of the already high level of blood lactic acid.

\section{Summary}

Three differing cases of glycogen storage disease are described. Each arose from a consanguinous marriage. One was a case of the classical von Gierke's disease, but the other two were less severe cases. The galactose tolerance test was used to investigate certain aspects of carbohydrate metabolism in the patients and the results are discussed in the light of recent biochemical knowledge of carbohydrate metabolism.

\section{REFERENCES}

Andersen, D. H. (1957). Miscellaneous disorders of metabolism: V. Glycogen storage diseases and galactosaemia. In Biochemical Disorders in Human Disease, ed. R. H. S. Thompson and E. J. King. Churchill, London.

Barker, S. B and Summerson, W. H. (1941). The colorimetric determination of lactic acid in biological material. J. biol. Chem. 138, 535 .

Calderbank, A., Kent, P. W., Lorber, J., Manners, D. J. and Wright, A. (1960). Biochemical investigation of a case of glycogen storage disease (von Gierke's disease). Biochem. J., 74, 223.

Cori, G. T. (1954). Glycogen structure and enzyme deficiencies in glycogen storage disease. Harvey Lect., 48, 145. glond Cori, C. F. (1952). Glucose-6-phosphatase of the liver in glycogen storage disease. J. biol. Chem., 199, 661 .

van Creveld, S. (1939). Glycogen disease. Medicine (Baltimore),

Fiske, C. H. and Subbarow, Y. (1925). The colorimetric determination of phosphorus. J. biol. Chem., 66, 375 . 
von Gierke, E. (1929). Hepato-nephromegalia glykogenica (Glykogenspeicherkrankheit der Leber und Nieren). Beitr. path. Anat., 82, 497.

Hauk, R. and Brown, D. H. (1959). Preparation and properties of uridinediphosphoglucose-glycogen transferase from rabbit muscle. Biochim. biophys. Acta, 33, 556.

- - Illingworth, B., Brown, D. H. and Cori, C. F. (1959). Enzyme of glycogen synthesis in glycogen-deposition disease. Ibid. 33, 554 .

Hers. H. G. (1959). Études enzymatiques sur fragments hépatiques. Application à la classification des glycogénoses. Rev. int. Hépat. 9,35.

Hepat., 9, A5. with glycogen-storage disease. Biochem. J., 76, 69P.

King, E. J. and Wootton, I. D. P. (1956). Micro-analysis in Medica Biochemistry, 3rd ed. Churchill, London.
Leloir, L. F. and Cardini, C. E. (1957). Biosynthesis of glycogen from uridine diphosphate glucose. J. Amer. chem. Soc., 79, 6340.

Lowrey, G. H. and Wilson, J. L. (1949). Observations on the treatment of a case of glycogen storage disease. J. Pediat., 35, 702.

Mason, H. H. and Andersen, D. H. (1941). Glycogen disease. Amer. J. Dis. Child., 61, 795.

(1955). Glycogen disease of the liver (von Gierke's disease) with hepatomata. Pediatrics, 16, 785.

Schwartz, R., Ashmore, J. and Renold, A. E. (1957). Galactose tolerance in glycogen storage disease. Ibid., 19, 585.

Sunderman, F. W., Copeland, B. E., Macfate, R. P., Martens, V. E. Naumann, H. N. and Stevenson, G. F. (1956). Manual of American Society of Clinical Pathologists workshop on glucose (condensed version). Amer. J. clin. Path., 26, 1355.

Zetterström, R. and Sörbo, B. (1956). Glycogen storage disease of the liver. Acta paediat. (Uppsala) 45, 269. 